\title{
INSTRUMENTOS JURÍDICO-ECONÔMICOS PARA PROTEÇÃO DO CLIMA NO BRASIL: TRIBUTAÇÃO, PAGAMENTO POR SERVIÇOS AMBIENTAIS E MDL
}

\author{
LEGAL AND ECONOMIC INSTRUMENTS FOR CLIMATE PROTECTION IN BRAZIL: TAXATION, \\ PAYMENTS FOR ENVIRONMENTAL SERVICES AND CDM
}

Luciana Della Nina Gambi*

\begin{abstract}
Resumo:
O presente artigo pretende analisar os mecanismos já instituídos no eixo climático de proteção do meio ambiente, notadamente aquele aplicável ao Brasil, verificando seus últimos resultados. Nesse contexto, será discutida a viabilidade de implementação de formas alternativas de fomento à redução de emissões de gases de efeito estufa e desenvolvimento de práticas que resultem em sequestro de carbono, o pagamento por serviços ambientais e a tributação do carbono, instrumentos esses a serem aplicados de forma paralela aos mecanismos já reconhecidos internacionalmente.

Palavras-chave: Proteção ambiental. Proteção do clima. Tributação do carbono. Pagamento por serviços ambientais. Mecanismo de desenvolvimento limpo.
\end{abstract}

\begin{abstract}
:
The present paper aims to analyze the existing climatic axis mechanisms for environmental protection, especially those applicable in Brazil, and their recent results. In such context, this paper will discuss whether is possible to implement alternative structures to induce the reduction of greenhouse gas emissions and the development of activities which will result in carbon sequestration: the payment for environmental services and a carbon tax, both instruments to be applied along with the mechanisms internationally recognized.
\end{abstract}

Keywords: Environmental protection. Climate protection. Carbon tax. Payment for environmental services. Clean development mechanism.

\section{Introdução}

A preocupação com o meio ambiente tem início com a percepção de que a humanidade deve ser capaz de atender às suas necessidades atuais garantindo, porém, essa mesma possibilidade às gerações futuras. ${ }^{1}$

No cenário internacional, desde 1970 vem aumentando a relevância dada às questões ambientais, no âmbito de discussões relativas ao crescimento e desenvolvimento

Luciana Della Nina Gambi é graduada em Direito pela Universidade de São Paulo, LLM em Direito Tributário Internacional pela Wirtschaftsuniversität Wien e mestranda em Direito na Universidade de São Paulo.

1 VEIGA, José Eli da. Para entender o desenvolvimento sustentável. 1. ed. São Paulo: Editora 34, 2015. p. 9. 
econômico, principalmente por conta da influência exercida pelo Programa das Nações Unidas para o Meio Ambiente (PNUMA). ${ }^{2}$

Ainda que a relevância do debate ambiental tenha se tornado latente, principalmente depois da Conferência de Estocolmo sobre o Meio Ambiente Humano de 1972, poucos resultados foram verificados no sentido de uma governança global de desenvolvimento sustentável. ${ }^{3}$

Diante, porém, da preocupação originada de novas pesquisas científicas a respeito do clima e do aquecimento global, a comunidade internacional concordou em aceitar a necessidade de redução de Gases de Efeito Estufa (GEE), entendendo ser necessário "cortar pela metade as emissões globais até 2050, para evitar aumento superior a dois graus centígrados em relação à temperatura média da era pré-industrial."4 A partir, pois, da criação da Convenção-Quadro das Nações Unidas sobre Mudança do Clima, o que se fez durante a Conferência sobre o Meio Ambiente e Desenvolvimento, ocorrida em 1992 no Rio de Janeiro, os países signatários da convenção firmaram o compromisso de proteção global do sistema climático.

Nesse contexto, desenvolveu-se o eixo climático de proteção do meio ambiente:

consolidado pelo Protocolo de Kyoto de 1997 - fruto da Convenção-Quadro da ONU sobre Mudança Climática de 1992 -, pelos panels do Painel Intergovernamental para a Mudança Climática (IPCC) estabelecido pelo Programa

\footnotetext{
2 "Os entendimentos da comunidade internacional sobre os cuidados exigidos pela conservação do meio ambiente têm sido muito mais intensos do que se costuma supor. Alguns poucos indicadores são suficientes para perceber que chega a ser frenético o processo político global com esse foco. Mesmo deixando de lado os acertos bilaterais, em apenas sete anos - 2005-2011 - foram assinados 22 acordos, 59 aditivos e 10 protocolos. A cada semestre, os corpos diplomáticos têm sido chamados a participar, em média, de quarenta reuniões de negociações multilaterais sobre questões ambientais. Embora esse tipo de cooperação tenha começado há muito mais tempo, uma indiscutível virada histórica ocorreu desde que começou a se tornar efetiva a influência do Programa das Nações Unidas para o Meio Ambiente (PNUMA, UNEP em inglês), com certeza a mais importante decisão da primeira megaconferência das Nações Unidas sobre o tema, realizada em Estocolmo em 1972." VEIGA, José Eli da. A desgovernança mundial da sustentabilidade. 1. ed. São Paulo: Editora 34, 2013. p. 45.

3 Conforme José Eli da Veiga, "é como se ainda não tivesse saído do papel o belo projeto de desenvolvimento sustentável consagrado na Rio-92." Id. Ibid., p. 79.

4 Ainda a respeito das mudanças climáticas e a concordância em reduzir as emissões de carbono: "Coordenados por Rockström, 29 pesquisadores de primeira linha procuraram "identificar e quantificar as fronteiras ecológicas planetárias que não devem ser transgredidas", porque isso "pode ajudar a evitar que as atividades humanas causem mudanças ambientais inaceitáveis (...). A primeira dessas fronteiras só poderia ser a da mudança climática, para a qual o processo conduzido pelo IPCC não leva a conclusões peremptórias, mas certamente permite a geração de consenso sobre o cenário probabilísticos menos temerário. Em especial, isso diz respeito à concentração de dióxido de carbono, em partes por milhão em volume ( $\mathrm{ppm}$ de $\left.\mathrm{CO}^{2}\right)$, que permitiria que o aumento da temperatura média não ultrapassasse os dois graus centígrados neste século. É provável que tal consenso científico agora esteja bem próximo dos $350 \mathrm{ppm}$ propostos pelo grupo." VEIGA, José Eli da. A desgovernança ... cit., p. 80 e 81.
} 
Ambiental das Nações Unidas (UNEP) em conjunto com a Organização Mundial para a Meteorologia (WMO), a partir de 1988, e também pelo Protocolo de Montreal de 1987, que traçou diretrizes para a proteção da Camada de Ozônio. ${ }^{5}$

Como órgão supremo da Convenção-Quadro das Nações Unidas sobre Mudança do Clima, as Conferências das Partes (COPs) têm atuação bastante relevante em relação ao assunto das mudanças climáticas, cabendo a esse órgão revisar a implementação da convenção, bem como de quaisquer outras regras específicas a serem adotadas.

Em sua última edição, realizada em dezembro de 2015, a $21^{\text {a }}$ Conferência das Partes (COP-21), sediada em Paris, deu origem a um amplo acordo internacional para o combate das mudanças climáticas. $\mathrm{O}$ acordo de Paris, pela primeira vez, uniu todas as nações para fins de uma causa comum, e fundada em responsabilidades comuns. $\mathrm{O}$ principal objetivo desse acordo é manter o aumento da temperatura terrestre abaixo de 2 graus Celsius, e empreender todos os esforços possíveis para que o aumento fique abaixo de 1,5 graus Celsius, em relação à temperatura verificada antes da Revolução Industrial. $\mathrm{O}$ acordo também pretende melhorar a atual capacidade de se lidar com os impactos decorrentes das mudanças climáticas. ${ }^{6}$

Prevê o acordo, ainda, que os países desenvolvidos devem providenciar recursos que auxiliem os países em desenvolvimento na mitigação e adaptação. ${ }^{7}$ Assim, e apesar da previsão quanto à existência de um mecanismo de financiamento, ainda são necessários esclarecimentos a respeito da operacionalização dessas transferências.

O presente estudo tem como objetivo verificar os resultados, no contexto brasileiro, de instrumentos criados pelo Protocolo de Kyoto no âmbito da proteção do clima, mais especificamente relativos ao controle de emissões de gases de efeito estufa, bem como algumas formas diferenciadas de indução e fomento a atividades que representem condutas protetivas ao meio ambiente no que diz respeito à redução do aumento da temperatura em relação à era pré-industrial.

Para tanto, após a apresentação dos mecanismos previstos no Protocolo de Kyoto, especialmente o Mecanismo de Desenvolvimento Limpo, aplicável no Brasil, o presente estudo abordará alguns resultados numéricos da aplicação do referido mecanismo. A partir daí, o estudo busca apresentar dois outros instrumentos que poderão

PUCCI, Rafael Diniz. Regulierungstechniken für Umweltdelikte und Restorative Justice. Revista da Faculdade de Direito da Universidade de São Paulo, São Paulo, v. 108, p. 531-541, jan./dez. 2013. Disponível em: <http://www.revistas.usp.br/rfdusp/article/view/67995/70852>. Acesso em: 29 abr. 2016.

6 Conforme informações disponíveis no site da ONU. Disponível em: $<$ http://newsroom.unfccc.int/unfcccnewsroom/finale-cop21/>. Acesso em: 25 abr. 2016.

7 Conforme art. 9 da Convenção de Paris. Disponível em: <https://unfecc.int/resource/docs/2015/cop21/eng/ 109r01.pdf>. Acesso em: 25 abr. 2016. 
ser utilizados no Brasil: o pagamento por serviços ambientais e a instituição de tributação sobre o carbono, especificando as características mais importantes a serem observadas nesse possível tributo.

\section{Mecanismo de Desenvolvimento Limpo}

A Política Nacional sobre Mudanças do Clima - PNMC, instituída por meio da Lei n. 12.187, de 29 de dezembro de 2009, positiva o compromisso voluntário assumido pelo Brasil de redução das emissões de GEE na $15^{\text {a }}$ Conferência das Partes COP-15. ${ }^{8}$ Referido compromisso aparece como uma das respostas oferecidas pelo governo brasileiro à tendência internacional de discussão de ações necessárias à conservação do meio ambiente, nesse caso especificamente voltada ao eixo climático do debate social relativo à proteção ambiental.

O compromisso voluntário de redução de GEE repercute em um dos mecanismos de flexibilização de redução de emissões previstos no protocolo de Kyoto, o Mecanismo de Desenvolvimento Limpo (MDL), que aparece ao lado de outros dois mecanismos, o comércio de emissões e a implementação conjunta. O MDL, por sua relevância, será abordado de forma mais específica abaixo. O comércio de emissões, por outro lado, é o mecanismo que permite que as cotas de emissão de GEE sejam comercializadas entre países que tenham definidas metas de redução, países esses elencados no Anexo 1 do Protocolo de Kyoto. Assim, estabelecida a meta de emissões de GEE, se um país tem cotas disponíveis, ou seja, se atinge um valor de emissão inferior ao da meta estabelecida, poderá negociar essas cotas com aqueles que tenham superado seu próprio limite. A implementação conjunta é mecanismo previsto no Protocolo que permite que os países do Anexo 1 ajam em conjunto para cumprir suas metas de emissão, de modo que um país transfira a outro ou adquira de outro unidades de redução de emissões.

Já o MDL é mecanismo aplicável aos países em desenvolvimento, não obrigados à redução de GEE, mas que, como o Brasil, voluntariamente estabeleçam metas, como as previstas no art. 12 da PNMC, e fomentem a redução de suas emissões ou projetos de sequestro de carbono da atmosfera. Por meio do MDL, os projetos que envolvam a redução de emissões de GEE ou sequestro de carbono podem ser qualificados

8 Conforme previsto no art. 12 da PNMC e de acordo com o quanto exposto no Plano Setorial de Mitigação e de Adaptação às Mudanças Climáticas para a Consolidação de uma Economia de Baixa Emissão de Carbono na Agricultura, coordenação da Casa Civil da Presidência da República, do Ministério da Agricultura, Pecuária e Abastecimento (MAPA) e do Ministério do Desenvolvimento Agrário (MDA): "Durante a 15 Conferência das Partes (COP-15), o governo brasileiro divulgou o seu compromisso voluntário de redução das emissões de gases de efeito estufa (GEE), estas projetadas para 2020, entre $36,1 \%$ e $38,9 \%$, estimando, naquele momento, uma redução destas emissões em torno de um bilhão de toneladas de $\mathrm{CO}^{2}$ equivalente $(\mathrm{t}$ $\mathrm{CO}^{2}$ eq)". 
como reduções certificadas de emissões (RCE), passíveis de negociação com os países do Anexo 1 que não tenham atingido suas metas de redução. A qualificação como reduções negociáveis depende de aprovação por entidade designada que, no Brasil, é a Comissão Interministerial de Mudança Global do Clima (CIMGC).

Alguns aspectos institucionais do MDL, no entanto, dificultam sua ampla utilização, como seu elevado custo de transação, compreendidos nele todos os valores gastos para a emissão do RCE, especificamente: “i) preparação de documentos; ii) validação e certificação pelas entidades operacionais designadas (EOD), incluindo custos de monitoramento; e iii) custos cobrados pelo Conselho Executivo do MDL e do país anfitrião". Além dos custos mencionados, projetos que se pretendam negociáveis como créditos de carbono ainda estão sujeitos ao risco de não serem certificados, fatos que podem ser acrescidos ao seu custo. ${ }^{9}$

Ademais, o elevado custo de transação do MDL poderá ter como consequência a deturpação do próprio fundamento da proteção ambiental justificadora desse mecanismo, conforme bem aponta Ana Maria de Oliveira Nusdeo: ${ }^{10}$

O mecanismo de desenvolvimento limpo pretende conjugar a eficiência dos mercados, pois os créditos gerados pelos projetos são comercializáveis em mercados secundários e até em bolsas de valores, com a realização dos objetivos de reduzir emissões, relacionada à adicionalidade dos projetos e à contribuição ao desenvolvimento sustentável dos países receptores. Essa heterogeneidade de objetivos tem rendido crítica ao mecanismo. O aspecto central delas é a tendência à aprovação de projetos de baixo custo, que resultam pouco adicionais e com contribuições medíocres ao desenvolvimento sustentável. Assim, a busca da eficiência, representada pelo interesse dos compradores de adquirir mais créditos por menores custos, tende a se sobressair em comparação aos demais objetivos.

Analisar a tendência mencionada de forma conjugada com a informação dos altos custos de transação do mecanismo demonstra o apertado espaço financeiro, dentro de uma negociação de créditos no mercado, para que o principal objetivo do MDL, o financiamento das atividades de redução de emissões e captura de carbono, seja efetivamente fomentado.

\footnotetext{
9 GUTIEEREZ, Maria Bernadete Sarmiento. Do MDL às NAMAS: perspectivas para o financiamento do desenvolvimento sustentável brasileiro. In: SEROA DA MOTTA, Ronaldo et al. Mudança do clima no Brasil: aspectos econômicos, sociais e regulatórios. Brasília: IPEA, 2011. p. 164 e ss.

10 NUSDEO, Ana Maria de Oliveira. Pagamento por serviços ambientais: sustentabilidade e disciplina jurídica. São Paulo: Atlas, 2012. p. 39 e 40.
} 


\subsection{Resultados do MDL no Brasil}

Apresentado o MDL como mecanismo a ser utilizado para fins de redução das emissões de GEE nos países em desenvolvimento, importante passar à verificação de seus resultados e sua efetividade no Brasil. Para tanto, foram analisados os últimos dados disponibilizados pela CIMGC, no Relatório Anual de Atividades relativo aos anos de 2013 e 2014. ${ }^{11}$ Importante salientar que a análise em questão será realizada pela perspectiva da quantidade de projetos apresentados, conforme informações disponibilizadas no Relatório da CIMGC.

Embora inicialmente houvesse expectativas de que a América Latina lideraria o mercado de MDL, ${ }^{12}$ isso não se confirmou. ${ }^{13}$ Até 31 de dezembro de 2014, a China liderava o número de projetos apresentados, respondendo o Brasil por apenas 4,4\% desse valor, conforme informações constantes do Relatório Anual de Atividades da CIMGC 2013-2014, abaixo reproduzidas:

\section{Atividades de projeto MDL por país até 31.dez.2014}

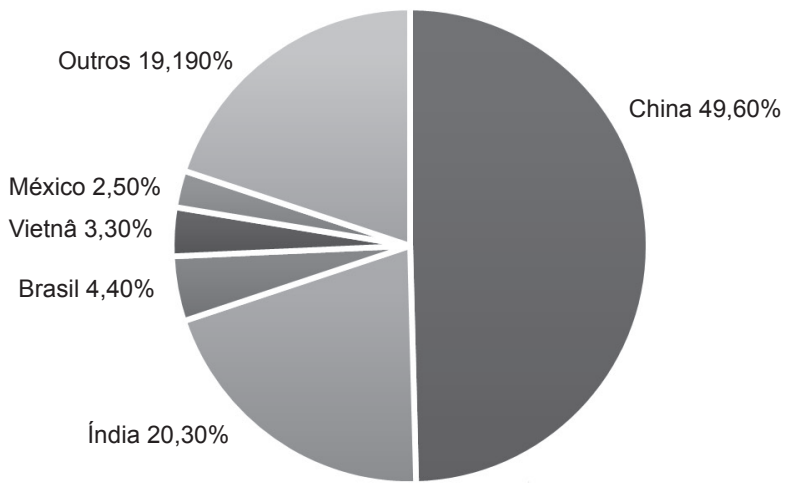

$11 \quad$ Disponível em: < http://www.mct.gov.br/index.php/content/view/362069/Relatorio_Anual_de_Atividades_ 2013_2014.html . Acesso em: 19 abr. 2016.

12 De acordo com Maria Bernadete Sarmiento Gutieerez: "a expectativa original, expressa em documento da Comissão Econômica para a América Latina e o Caribe (Cepal) (2004), era a de que a América Latina ocuparia papel de liderança absoluta no mercado de MDL devido a um conjunto de fatores, incluindo instituições adequadas à aprovação de projetos e ao apoio governamental, além de oferta potencial de projetos bastante variada, com destaque a projetos hidroelétricos, eólicos, de eficiência energética, de gestão de resíduos, entre outros." GUTIEEREZ, Maria Bernadete Sarmiento. Do MDL às NAMAS ... cit., p. 167. 13 Id. Ibid. 
Além da relativa baixa participação do Brasil no volume total de projetos apresentados no âmbito do MDL, verifica-se nos últimos dois anos (2013 e 2014) queda bastante relevante na quantidade de projetos apresentados à CIMGC, informações que se extraem do mesmo Relatório Anual de Atividades da CIMGC, referente aos anos de 20132014 e encontram-se reproduzidas no quadro a seguir:

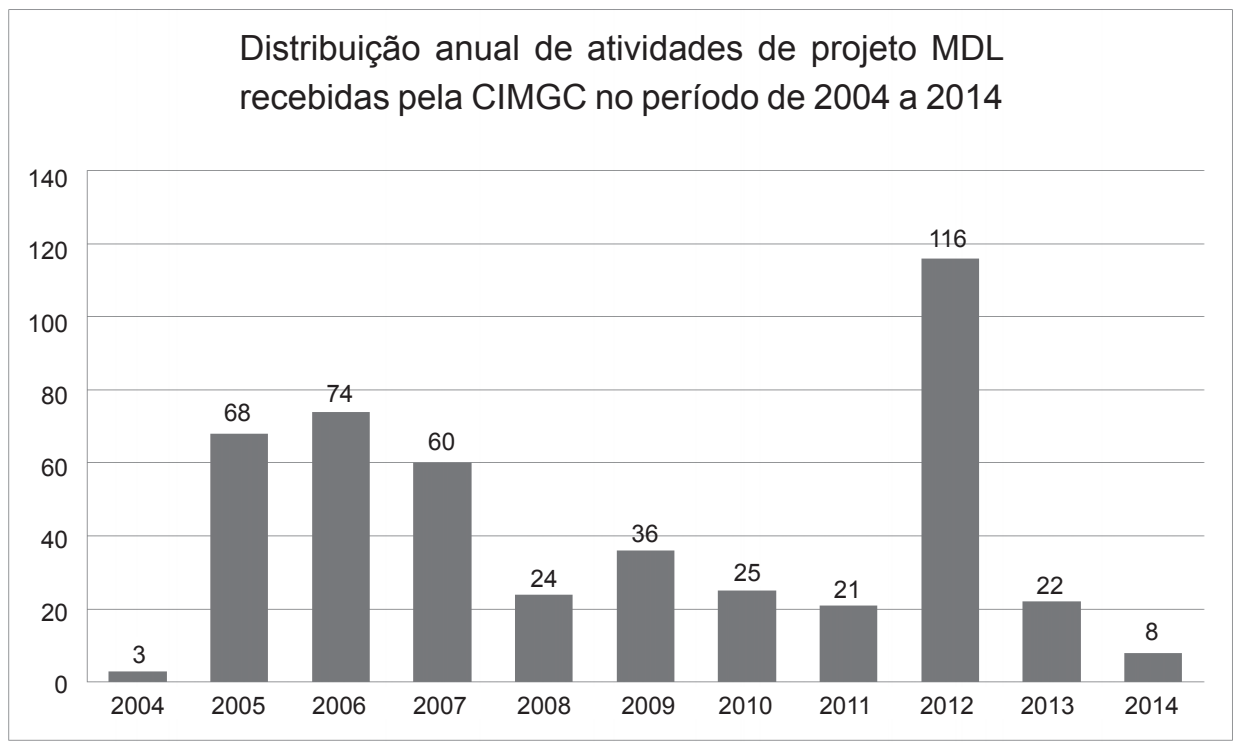

Aponta o referido Relatório que a redução de projetos apresentados em relação ao ano de 2012, período no qual o maior número de projetos foi apresentado no Brasil, é característica global e decorre das incertezas a respeito do futuro do MDL e da própria continuidade do Protocolo de Kyoto, considerando-se o término do seu primeiro período e as dificuldades nas negociações internacionais. Além disso, o grande volume de projetos apresentados durante o ano de 2012 pode ser justificado pela decisão da União Europeia de, a partir de 31 de dezembro de 2012, comprar RCEs apenas de países menos desenvolvidos - fato que fez com que os agentes que estavam desenvolvendo projetos passíveis de credenciamento como RCEs acelerassem seus registros dentro desse prazo. ${ }^{14}$

14 A esse respeito, citamos trecho do Relatório Status dos projetos de MDL no Brasil, relativo ao primeiro período de execução do compromisso do Protocolo de Kyoto, de 2008 a 2012 "O Protocolo de Quioto estipulou que as metas de quantificação de redução e limitação de emissão de gases de efeito estufa devem ser reduzidas em pelo menos 5,2\% em relação aos níveis de GEE de 1990. Essas metas deveriam ser atingidas no período compreendido entre 2008 e 2012, conhecido como $1^{\circ}$ período de compromissos do Protocolo de Quioto. Durante esse período, diversos fatores e decisões influenciaram os resultados da implementação do MDL. Entre eles, a incerteza sobre a renovação do Protocolo e a decisão da União 
Se essa falta de coordenação internacional relativa ao controle das emissões de GEE, e tendência de incertezas quanto à continuidade, ou não, do Protocolo de Kyoto continuar a influenciar negativamente as atividades de redução de emissões voluntárias e busca por formas de sequestro de carbono no Brasil, formalizadas pelo MDL, o objetivo fundamental da própria instituição do eixo climático de proteção do clima - que pode ser resumido na tentativa de manutenção do aumento da temperatura global em apenas 2 graus Celsius em relação à temperatura verificada antes da revolução industrial - poderá ser prejudicado, além de correr o risco de ser inviabilizado. Considerando-se a proposta acordada na COP-21, na qual é tido como objetivo fazer com que o aumento da temperatura terrestre não ultrapasse 1,5 graus Celsius, será necessária ainda maior coordenação entre toda comunidade internacional.

Mantido esse cenário, não será fácil a utilização de mecanismos de flexibilização das reduções de emissão de GEE, a exemplo do MDL, como instrumento de proteção ambiental do eixo climático em países como o Brasil.

Importante salientar, ainda, que, embora o MDL esteja inserido em uma sistemática que visa a redução das emissões de GEE, o uso desse instrumento, por si só, não implica a direta redução de GEE na atmosfera. Isso porque o mecanismo contabiliza reduções verificadas em um país em desenvolvimento e atribui o mesmo valor como permissão de emissão a um país constante do Anexo 1 do Protocolo de Kyoto. Ou seja, há uma "compensação" de emissões de GEE: o que não é emitido em um país, poderá ser emitido em outro. Ainda assim, o MDL deve ser considerado como instrumento de incentivo ao desenvolvimento sustentável, vez que permite a comercialização de créditos entre países desenvolvidos e em desenvolvimento.

Em um tal cenário, passa a ser relevante o estudo de formas alternativas para o financiamento e fomento desse tipo de atividade, que poderão atuar em conjunto a mecanismos já instituídos, como o MDL. Nesse contexto, serão analisados o Pagamento por Serviços Ambientais e uma possível Tributação do Carbono.

Europeia - principal comprador de RCEs - de, após 31 de dezembro de 2012, comprar apenas RCEs de projetos de países menos desenvolvidos (LCDs). O último fato levou os desenvolvedores de projetos, principalmente do Brasil, China e Índia - os representantes de aproximadamente $75 \%$ dos projetos do mundo - a acelerarem os procedimentos para registro de projetos. O resultado foi um número expressivo de projetos sendo submetido às ANDs e ao registro na UNFCCC em 2012, não apenas pelo Brasil, mas por todo o mundo. Por conseguinte, o Secretariado Executivo da UNFCCC apresentou uma demanda reprimida de projetos a serem avaliados durante o período. Uma grande parte desses projetos foi avaliada apenas em 2013, tendo a data de registro sido considerada como aquela da data de submissão do projeto na UNFCCC." Relatório Status dos projetos no âmbito do Mecanismo de Desenvolvimento Limpo (MDL) no Brasil e no mundo $-1^{\circ}$ Período de compromisso do Protocolo de Quioto (2008-2012) (Data final de coleta de dados: 12/2/2014). Disponível em: <http://www.mct.gov.br/upd_blob/0232/232099.pdf>. Acesso em: 19 abr. 2016. 


\section{Pagamento por Serviços Ambientais}

Serviços ambientais podem ser definidos como o "fluxo de materiais, energia e informação provenientes do estoque de capital natural que se combinam com as atividades de capitais industriais e humanos para a produção do bem-estar humano". ${ }^{15} \mathrm{~A}$ valoração dos serviços ambientais passa a ser relevante a partir da tomada de consciência de que esses serviços nunca foram devidamente quantificados nem considerados na dinâmica dos processos produtivos, ${ }^{16}$ colocando em risco, inclusive, a própria existência dos seres humanos, vez que o caráter limitado dos recursos ambientais não conseguirá suportar um crescimento incontrolado das necessidades humanas. ${ }^{17}$

Uma vez atribuído valor aos serviços ambientais, a discussão acerca da proteção do meio ambiente deve considerar a possibilidade de remuneração a ser conferida para condutas que tenham resultados protetivos. Considera-se pagamento por serviços ambientais (PSA) "transações entre duas ou mais partes envolvendo a remuneração àqueles que promovem a conservação, recomposição, incremento ou manejo de áreas de vegetação considerada apta a fornecer certos serviços ambientais". ${ }^{18}$

15 No original: "Ecosystem services consist of flows of materials, energy, and information from natural capital stocks which combine with manufactured and human capital services to produce human welfare." CONSTANZA, Robert; D'ARGE, Ralph et al. The value of the world's ecosystem services and natural capital. Nature, London, v. 387, n. 6.630, p. 253-260, May 1997. p. 254.

16 DERANI, Cristiane. Direito ambiental econômico. 3. ed. São Paulo: Saraiva, 2008. p. 89 e ss.

17 Soma-se a isso o fato de que a utilização do meio ambiente, especialmente no que diz respeito aos poluentes lançados, sujeita-se ao que foi denominado de "tragédia dos bens comuns", segundo a qual, tratando-se de bens coletivamente utilizados - como o meio ambiente -, quem deles se utiliza buscará sempre maximizar as suas próprias vantagens, o que levará, em última instância, à inviabilidade desses bens comuns suportarem a utilização coletiva. HARDIN exemplifica a ideia da tragédia dos comuns descrevendo a utilização de um pasto comum por vários pastores: "Picture a pasture open to all. It is to be expected that each herdsman will try to keep as many cattle as possible on the commons. Such an arrangement may work reasonably satisfactorily for centuries because tribal wars, poaching, and disease keep the numbers of both man and beast well below the carrying capacity of the land. Finally, however, comes the day of reckoning, that is, the day when the long-desired goal of social stability becomes a reality. At this point, the inherent logic of the commons remorselessly generates tragedy. As a rational being, each herdsman seeks to maximize his gain. Explicitly or implicitly, more or less consciously, he asks, "What is the utility to me of adding one more animal to my herd?" This utility has one negative and one positive component. 1) The positive component is a function of the increment of one animal. Since the herdsman receives all the proceeds from the sale of the additional animal, the positive utility is nearly +1.2 ) The negative component is a function of the additional overgrazing created by one more animal. Since, however, the effects of overgrazing are shared by all the herdsmen, the negative utility for any particular decision-making herdsman is only a fraction of - 1 . Adding together the component partial utilities, the rational herdsman concludes that the only sensible course for him to pursue is to add another animal to his herd. And another: and another... But this is the conclusion reached by each and every rational herdsman sharing a commons. Therein is the tragedy. Each man is locked into a system that compels him to increase his herd without limit--in a world that is limited. Ruin is the destination toward which all men rush, each pursuing his own best interest in a society that believes in the freedom of the commons. Freedom in a commons brings ruin to all." HARDIN, Garrett. The tragedy of the commons. Science, Washington D.C, v. 162, n. 3.859, p. 1.243-1.248, Dec. 1968.

18 NUSDEO, Ana Maria de Oliveira. Pagamento por serviços ... cit., p. 69. 
De acordo com a sistemática do PSA, o desenvolvimento de atividades que forneçam serviços ambientais não somente deve ser incentivado, mas pode ser elegível para recebimento de remuneração. Assim, no contexto do eixo climático de proteção do meio ambiente, seriam passíveis de remuneração atividades aptas a reduzir as emissões de GEE ou aquelas que resultem em sequestro de carbono da atmosfera.

Nesse sentido, atividades florestais assumem caráter de grande relevância para o Brasil. Uma das formas, aliás, de viabilização do cumprimento de metas assumidas voluntariamente pelo Brasil é o controle do desmatamento, medida que compõe um conjunto de atividades florestais que viabilizam o sequestro de carbono, como atividades de plantio de florestas e manejo e gestão de florestas já existentes. ${ }^{19} \mathrm{Na}$ hipótese de se verificar um futuro promissor aos instrumentos de cooperação internacional para redução das emissões de GEE, a exemplo daqueles previstos no Protocolo de Kyoto, esse seria instrumento de grande importância para o desenvolvimento sustentável de países em desenvolvimento, já que representam projetos de MDL de reflexo econômico menos restritivo quando comparados a medida diferente, como a redução de gasto energético, ${ }^{20}$ podendo, inclusive, ser fonte de créditos de carbono negociáveis como mercadorias, adquirindo valor de mercado. ${ }^{21}$

Mesmo que fora da sistemática do MDL, a ideia de se remunerar os serviços ambientais pode funcionar como forma de fomento e mesmo financiamento de atividades protetivas no âmbito local ou nacional. Tomando-se como exemplo as atividades florestais já mencionadas, e que são capazes de viabilizar o sequestro e estocagem de carbono, o pagamento pelo serviço de reflorestamento ou manutenção de uma floresta seria uma forma econômica de compensar os custos verificados nessas atividades - e que justamente gerarão o serviço ambiental de sequestro e estocagem de carbono. ${ }^{22}$

19 NUSDEO, Ana Maria de Oliveira. Pagamento por serviços ... cit., p. 40.

20 SEROA DA MOTTA, Ronaldo. A política nacional sobre mudança do clima: aspectos regulatórios e de governança. In: SEROA DA MOTTA, Ronaldo. (Ed.) et al. Mudança do clima no Brasil: aspectos econômicos, sociais e regulatórios. Brasília: IPEA, 2011. p. 35.

21 Conforme Ronaldo Seroa da Motta, "No Brasil já existem mecanismos de mercado de carbono para o fomento aos projetos de redução de emissão de gases de efeito estufa, no âmbito do MDL, com a implantação de um sistema para a negociação de créditos de carbono na Bolsa de Mercadorias e Futuros (BM\&F), denominado mercado brasileiro de redução de emissões (MBRE).” Id. Ibid., p. 37.

22 Especificamente a respeito do recebimento de compensação pelo desmatamento evitado, importante salientar as discussões a respeito da Redução de Emissões por Desmatamento ou Degradação Florestal em Países em Desenvolvimento (REDD, do inglês Reducing Emissions from Deforestation and Forest Degradation in Developing Countries). Por meio do REDD, pretende-se remunerar os responsáveis pela manutenção de florestas já existentes. Sobre o assunto: SHELLARD, Sofia; MOZZER, Gustavo Barbosa. Oportunidades e desafios relativos à implementação de mecanismos de REDD. In: SEROA DA MOTTA, Ronaldo. (Ed.) et al. Mudança do clima no Brasil: aspectos econômicos, sociais e regulatórios. Brasília: IPEA, 2011. p. 179 e ss. 
Sem o recebimento da remuneração, teríamos, na melhor das hipóteses, uma situação em que o agente que empenha recursos em atividade florestais tem gastos para esse fim, mas não recebe compensação financeira em troca. De outro lado, a coletividade, que auferirá os benefícios da atividade protetiva desse agente, não incorreu em nenhum custo. Assim, a sistemática de pagamento por serviços ambientais permite corrigir a discrepância econômica verificada na hipótese em que um só agente incorre em custos para o desenvolvimento de uma atividade protetiva que beneficiará a toda uma coletividade inerte.

O mesmo pode ser dito em relação, como exemplo, aos proprietários e produtores rurais que são obrigados a manter Áreas de Preservação Permanente ${ }^{23}$ e Reservas Legais. ${ }^{24}$ Assumindo que a maior parte dos mencionados proprietários rurais tenha terras produtivas, não se discute que eles terão de arcar com gastos para a manutenção das referidas áreas, ao mesmo tempo em que verificarão diminuição de sua produção nos locais destinados à conservação do meio ambiente, ainda que, nesse caso, o Código Florestal (Lei n. 12.651/2012) preveja como compensação por medidas de conservação ambiental a possibilidade de dedução de áreas APPs e Reserva Legal da base de cálculo do Imposto sobre a Propriedade Territorial Rural - ITR, conforme art. 41, II, "c" do referido Código. Embora incorram em custos diretos, mais uma vez o benefício gerado por tais custos não estará restrito aos produtores, mas é necessário para toda a coletividade. O pagamento pelos serviços florestais prestados pelos referidos produtores serviria como forma de diluir os custos envolvidos na prestação desse serviço de benefício difuso.

Além da sistemática estabelecida pelos já referidos PSA e MDL, outro método a ser utilizado com a mesma finalidade pode ser pensado a partir da instituição de um tributo como forma de viabilizar a proteção ambiental, assunto que será tratado a seguir.

${ }_{23}$ Conforme art. $3^{\circ}$, II, do Código Florestal (Lei n. 12.651/2012): “Área de Preservação Permanente - APP: área protegida, coberta ou não por vegetação nativa, com a função ambiental de preservar os recursos hídricos, a paisagem, a estabilidade geológica e a biodiversidade, facilitar o fluxo gênico de fauna e flora, proteger o solo e assegurar o bem-estar das populações humanas."

24 Conforme art. $3^{\circ}$, III, do Código Florestal (Lei n. 12.651/2012): "Reserva Legal: área localizada no interior de uma propriedade ou posse rural, delimitada nos termos do art. 12, com a função de assegurar o uso econômico de modo sustentável dos recursos naturais do imóvel rural, auxiliar a conservação e a reabilitação dos processos ecológicos e promover a conservação da biodiversidade, bem como o abrigo e a proteção de fauna silvestre e da flora nativa." 
4. Tributação como instrumento de proteção ambiental

Reuven S. Avi-Yonah e David M. Uhlmann, no contexto de um modelo norte-americano de controle da emissão de GEE, entendem que um sistema que preveja a tributação sobre o carbono, aqui compreendido como a emissão de gases poluentes e de efeito estufa, é mais eficiente do que a atual sistemática de limitação de emissões e negociação de cotas para fins de combater as mudanças climáticas. ${ }^{25}$

Apontam os autores que a tributação do carbono teria as seguintes vantagens: simplicidade, geração de receita, certeza de custo e clara sinalização de que a emissão de GEE gera efeitos nocivos. ${ }^{26}$

A simplicidade para aplicação de um tributo sobre o carbono decorreria da própria matriz tributária: basta estabelecer uma alíquota a incidir sobre uma determinada quantidade de carbono emitido (tonelada de carbono), aceitando-se créditos para atividades que resultem no sequestro efetivo de carbono, além de se estabelecer que as exportações seriam isentas. $\mathrm{O}$ tributo seria devido em atividades de produção (upstream), facilitando sua arrecadação. Para os autores, essa simplicidade se contrapõe ao complexo sistema de limitação da quantidade de emissão e negociação de cotas sobressalentes (cap and trade), vez que esse sistema exige o estabelecimento de valores limite, criação e distribuição de permissões de emissão, além de ser necessária autoridade administrativa com função específica de monitoramento e controle do sistema.

Além da simplicidade, elencam os autores o benefício de a tributação sobre o carbono gerar receita, que deveria ser segregada e destinada a investimentos na área, ao contrário da sistemática do cap and trade, na qual licenças de carbono costumam não ter custo, e a certeza de custo das transações que envolvam a emissão de carbono, vez que a carga tributária estará limitada pela alíquota definida.

Por fim, teria a imposição de tributo sobre o carbono a adicional característica positiva de sinalizar ao mercado em geral que a emissão de GEE, como atividade poluidora, importa externalidade negativa a toda a coletividade, cabendo às empresas poluidoras a internalização desse custo por meio do pagamento do tributo, ao contrário da sistemática do cap and trade, que reflete a ideia de que seria permitido a qualquer agente realizar atividades poluentes, desde que tais agentes estivessem dispostos a pagar por isso.

25 AVI-YONAH, Reuven S.; UHLMANN, David M. Combating global climate change: why a carbon tax is a better response to global warming than cap and trade. Stanford Environmental Law Journal, Stanford, v. 28, p. 3-50, 2009. p. 3-50.

26 Id. Ibid., p. 36 e seguintes. 
As desvantagens apontadas pelos autores em relação à instituição de um tributo que incida sobre as emissões de carbono dizem respeito à resistência política, vez o aumento da carga tributária é sempre considerado fato negativo aos contribuintes, incerteza quanto aos benefícios, eventuais concessões de isenções, que poderiam se tornar permanentes para determinados setores industriais, e a dificuldade de coordenação internacional. ${ }^{27}$

A respeito das mencionadas desvantagens, acreditamos que, a depender da matriz de incidência de um tributo sobre o carbono, a maior parte das dificuldades referidas poderia ser minimizada.

Inicialmente, a resistência política à instituição de tributação sobre o carbono poderia ser reduzida se sua apresentação fosse vinculada a discussões públicas a respeito da necessidade de proteção ambiental, especificamente de redução das emissões de GEE. Mais importante ainda, a cobrança de um tributo sobre as emissões de GEE deveria estar restrita aos setores produtivos responsáveis por grande parte das emissões de GEE, ou seja, atividades industriais notadamente poluentes. Restringir a incidência desse tributo aos grandes poluidores, a um só tempo, evitaria uma repercussão pública negativa a respeito - já que os agentes que não atuam de forma ambientalmente prejudicial não estariam diretamente sujeitos à nova carga fiscal, bem como permitiria uma adequada aplicação do princípio do poluidor-pagador, que teria a função de internalizar os custos correspondentes às atividades de degradação do meio ambiente, ${ }^{28}$ de forma a fomentar a ideia de que o desenvolvimento da economia deve ser sustentável.

Quanto à incerteza a respeito dos benefícios efetivamente oriundos da instituição de um tributo sobre as emissões de GEE, entendemos que essa verificação dependeria, em grande parte, da concretização do princípio do poluidor-pagador e do surgimento de uma consciência ambiental de forma paralela à imposição tributária, com a finalidade de disseminar comportamentos mais protetivos ao meio ambiente por toda a sociedade. De qualquer forma, a instituição de tributação sobre o carbono poderia, no mínimo, gerar receita a ser utilizada em pesquisas ambientais e para desenvolvimento de tecnologias mais sustentáveis.

A respeito da concessão de isenções fiscais, parece-nos que esse tipo de instrumento poderia ser mais utilizado como forma de incentivo à proteção do meio ambiente do que como meio de garantir que setores industriais continuassem a ser grandes poluidores sem que tivessem que pagar por isso. Não sendo utilizados como meio de impedir que a nova carga tributária incida sobre os setores considerados poluidores, os incentivos fiscais poderiam ser concedidos aos agentes que praticassem condutas

$27 \quad$ Id. Ibid., p. 45 e seguintes.

28 LEITE, José Rubens Morato (Coord.). Manual de direito ambiental. São Paulo: Saraiva, 2015. p. 102. 
protetivas, seja reduzindo suas emissões de GEE, seja desenvolvendo atividades que permitam o sequestro de carbono. ${ }^{29}$ Ademais, o desenvolvimento de atividades protetivas ou, no mínimo, menos poluentes poderia justificar um tratamento favorecido, do ponto de vista fiscal, dos agentes atuantes no mercado. ${ }^{30}$

Por fim, da mesma forma como abordado pelos autores, entendemos que a tributação sobre o carbono enfrentaria, de fato, certa dificuldade em relação à coordenação internacional, pelo menos enquanto não há um modelo global de tributação do carbono. Contudo, considerando-se as incertezas verificadas na aplicação de um dos instrumentos oriundos do Protocolo de Kyoto, apontado pelo Relatório Anual de Atividades da CIMGC, referente aos anos de 2013-2014, como justificativa para a queda do número de projetos apresentados para fins do MDL, parece-nos que a necessidade de coordenação internacional pode representar grave entrave a qualquer tipo de mecanismo tendente a reduzir a emissão de GEE. Sendo assim, mais importante seria a criação de um mecanismo eficiente nos seus propósitos de controle do clima, ainda que restrito ao âmbito interno dos países, do que a manutenção de um mecanismo internacionalmente reconhecido, mas cuja aplicação não tem se mostrado muito ampla, como o MDL.

\subsection{Espécies tributárias e tributação do carbono}

Firmadas as premissas no sentido da efetividade da instituição de um tributo ambiental para os fins colimados, notadamente o desestímulo a práticas nocivas e a arrecadação vinculada à implementação de projetos voltados ao meio ambiente, passemos a analisar, dentro das possibilidades constitucionais brasileiras, a espécie tributária que poderia se adequar a esses fins.

A interpretação conjunta do Código Tributário Nacional e da Constituição Federal, de 1988, levou o Supremo Tribunal Federal (STF) a firmar o entendimento segundo o qual, no Brasil, há cinco espécies tributárias, a saber, os impostos, as taxas, o empréstimo compulsório, as contribuições de melhoria e as contribuições. ${ }^{31}$

29 Nesse sentido: "Os incentivos fiscais assumem papel preponderante para a realização da tributação extrafiscal, direcionando as condutas dos contribuintes para atingirem os objetivos e princípios assinalados em nossa Constituição Federal." AMARAL, Paulo Henrique do. Direito tributário ambiental. São Paulo: Revista dos Tribunais, 2007. p. 194.

30 A esse respeito: “O direito ao meio ambiente saudável é um direito social universal, previsto no art. $6^{\circ}$ da CF/1988 - combinando saúde e segurança - e os meios implementados para provê-lo - desonerações tributárias a determinadas pessoas jurídicas - justificam o tratamento privilegiado àquelas mesmas pessoas jurídicas em cuja atividade esteja inserida a sustentabilidade ambiental". BORBA, Fernanda Estima; FRANÇA, Vladimir da Rocha. O postulado da proporcionalidade na tributação indutora: aplicação e efetividade na defesa do meio ambiente. Revista Tributária e de Finanças Públicas, São Paulo, n. 89, p. 102-125, nov./dez. 2009. p. 121.

31 Conforme julgado pelo STF na ADI n. 447, Rel. Min. Octavio Gallotti, voto do Min. Carlos Velloso, 
A par das espécies tributárias atualmente existentes, cumpre, de início, rechaçar a aplicabilidade de algumas delas para o possível modelo de um tributo a incidir sobre o carbono. Em primeiro lugar, pode-se afastar a instituição de um imposto nesse sentido, já que os impostos não podem ter sua receita vinculada a qualquer despesa previamente a sua arrecadação. ${ }^{32}$ Essa característica dos impostos já afasta seu uso como tributo ambiental, que teria caráter fiscal para arrecadar fundos em prol do meio ambiente.

As taxas, por sua vez, são tributos vinculados a atividade estatal. No caso, o tributo ambiental não deve ser precedido de qualquer atividade estatal, mas sim de atividade indesejável do particular, afastando-se, assim, qualquer possibilidade de falar-se em taxas.

Os empréstimos compulsórios e contribuições de melhoria não gozam de melhor sorte. O primeiro tem como implícita a ideia de devolução dos valores após a utilização necessária, o que não se coaduna com a tributação da emissão de GEE, já que a necessidade de melhoramento das condições ambientais é um valor sempre renovável. As contribuições de melhoria, por sua vez, dependem de realização de obra pública que implique valorização imobiliária, sendo, pois, patentemente incompatível.

Chega-se, pois, por exclusão, às contribuições. Passemos a uma análise mais detida dessa espécie tributária.

A competência tributária para instituição das contribuições sociais está prevista no art. 149 da Constituição, que outorga tal competência, via de regra, à União.

As contribuições podem ser definidas como espécie tributária cujo fato gerador é desvinculado de uma atividade estatal, mas o produto é diretamente afetado a um fim relativo ao interesse público. A destinação de seu produto é a principal distinção dessa espécie em relação aos impostos. ${ }^{33}$

O STF definiu que as contribuições se subdividem em: destinadas à seguridade social, de intervenção no domínio econômico e de interesse de categoria profissional ou econômica. ${ }^{34}$

julgamento em 5.6.1991, Plenário, DJ de 5.3.1993.

32 Ressalvadas as exceções do art. 167, IV, da Constituição Federal: “Art. 167. São vedados:

(...)

IV - a vinculação de receita de impostos a órgão, fundo ou despesa, ressalvadas a repartição do produto da arrecadação dos impostos a que se referem os arts. 158 e 159, a destinação de recursos para as ações e serviços públicos de saúde, para manutenção e desenvolvimento do ensino e para realização de atividades da administração tributária, como determinado, respectivamente, pelos arts. 198, $\S 2^{\circ}, 212$ e 37, XXII, e a prestação de garantias às operações de crédito por antecipação de receita, previstas no art. $165, \S 8^{\circ}$, bem como o disposto no $\S 4^{\circ}$ deste artigo; (Redação dada pela Emenda Constitucional n. 42, de 19.12.2003)"

33 Conforme AMARO, Luciano da Silva. Direito tributário brasileiro. 17. ed. São Paulo: Saraiva, 2011. p. 107.

34 Nesse sentido, citamos as seguintes decisões do STF: RE n. 401.823-AgR, Rel. Min. Ayres Britto, julgamento em 28.9.2004, Primeira Turma, DJ de 11.2.2005 e ADI n. 447, Rel. Min. Octavio Gallotti, voto 
Em uma primeira análise, já é possível descartar a utilização de contribuições de interesse de categoria profissional ou econômica, que são aquelas destinadas às pessoas jurídicas fiscalizadoras do exercício de profissões, o que as leva a serem chamadas de parafiscais.

Restariam, então, a contribuição de intervenção no domínio econômico e a contribuição social.

Abordando a contribuição social, sua finalidade é a arrecadação para atuação da União na efetivação de valores sociais, cuja extensão deve ser extraída da parte da Constituição destinada à Ordem Social, podendo, dessa forma, destinar-se a custear questões atinentes à seguridade social, educação, desporto, meio ambiente etc. ${ }^{35}$

A rigor, portanto, seria juridicamente possível a criação de uma contribuição social com a finalidade de arrecadar fundos destinados à proteção do meio ambiente. Podemos citar, nesse sentido, o exemplo da Contribuição prevista no art. 22, II, da Lei n. 8.212/91, denominada Contribuição decorrente do Risco Ambiental do Trabalho. Referida contribuição, além de custear a aposentadoria especial (prevista no art. 57 e seguintes da Lei n. 8.213/91), aquela destinada aos segurados expostos a condições lesivas à saúde, também tem alíquotas crescentes conforme o risco ao qual o empregador expõe seus empregados, que podem ser majorados de acordo com o Fator Acidentário de Prevenção. Sem adentrar a qualquer discussão sobre a correção do método do FAP, sua instituição certamente tem como finalidade o desestímulo a práticas lesivas à saúde do trabalhador, demonstrando sua extrafiscalidade.

Assim, a exemplo da mencionada contribuição, parece possível a instituição de uma contribuição social que incida sobre atividades que resultem em emissão de GEE, com vistas a (i) desestimular tal conduta e (ii) arrecadar fundos para adotar as providências necessárias ao reparo do meio ambiente lesado, o que, sem dúvidas, deve ser custeado pelo agente poluidor. Muito possivelmente, para desestimular a emissão de carbono, a contribuição deveria ter, como hipótese de incidência e base de cálculo, alguma grandeza relativa a tal emissão.

Nesse sentido, passaremos a discorrer a respeito das características das contribuições de intervenção no domínio econômico, e sua adequação como espécie tributária a ser utilizada como veículo de instrumentalização de uma tributação do carbono no Brasil.

do Min. Carlos Velloso, julgamento em 5.6.1991, Plenário, DJ de 5.3.1993.

35 Conforme COSTA, Regina Helena. Curso de direito tributário: Constituição e Código Tributário Nacional, 1. ed. São Paulo: Saraiva, 2009. p. 131. 


\subsection{Contribuição de Intervenção no domínio econômico}

A contribuição de intervenção no domínio econômico (CIDE) pode ser definida como o tributo que instrumentaliza uma intervenção estatal para concretização de princípios constitucionais. ${ }^{36}$ Surge do papel interventor do Estado, devendo ser instituída com finalidade específica e atinente a uma atuação estatal. Por trás de referida contribuição, há a lógica de que o causador da intervenção estatal deve custeá-la, sendo, pois, o contribuinte da CIDE.

No caso da instituição de um tributo que tenha como finalidade a redução de emissões de GEE, a CIDE demonstra-se adequada seja pelo caráter interventivo do Estado em defesa do meio ambiente a ser custeada pelos poluidores, em outras palavras, em uma ótica extrafiscal, seja pela inerente arrecadação, que obviamente seria vinculada a um fundo voltado à proteção do meio ambiente.

A fixação de seu fato gerador como a emissão de GEE e a fixação de sua base de cálculo pela quantidade de toneladas de GEE emitidas por um agente ${ }^{37}$ atuariam $^{-}$ como nítidos inibidores para os poluidores. Ademais, tratando-se de contribuição especial, o sujeito ativo da suposta CIDE seria a União, devendo o sujeito passivo de a obrigação tributária ser empresas que exerçam atividades relacionadas à emissão de GEE.

Assim, pode-se dizer que, pelas suas características, a CIDE se demonstra como um tributo adequado para instrumentalizar a intervenção estatal em defesa do

36 A respeito da justificação das CIDEs, Luís Eduardo Schoueri: "Tal como se disse com relação às contribuições sociais, também as contribuições especiais justificam-se por sua finalidade: servir de instrumento de atuação da União nas respectivas áreas. Assim, as Contribuições de Intervenção no Domínio Econômico proveem recursos para a União efetuar tal intervenção, enquanto as contribuições de interesse de categoria profissional ou econômica são voltadas a prover recursos para a União atuar no interesse daquelas categorias.” SCHOUERI, Luís Eduardo. Direito tributário. São Paulo: Saraiva, 2011. p. 213.

37 Obedecendo ao quanto previsto pelo parágrafo $2^{\circ}$, III, "b" do art. 149, da Constituição Federal de 1988:

Art. 149. Compete exclusivamente à União instituir contribuições sociais, de intervenção no domínio econômico e de interesse das categorias profissionais ou econômicas, como instrumento de sua atuação nas respectivas áreas, observado o disposto nos arts. 146, III, e 150, I e III, e sem prejuízo do previsto no art. $195, \S 6^{\circ}$, relativamente às contribuições a que alude o dispositivo.

(...)

$\S 2^{\circ}$ As contribuições sociais e de intervenção no domínio econômico de que trata o caput deste artigo: (Incluído pela Emenda Constitucional n. 33, de 2001).

I - não incidirão sobre as receitas decorrentes de exportação; (Incluído pela Emenda Constitucional n. 33, de 2001).

II - incidirão também sobre a importação de produtos estrangeiros ou serviços;

III - poderão ter alíquotas:

a) ad valorem, tendo por base o faturamento, a receita bruta ou o valor da operação e, no caso de importação, o valor aduaneiro;

b) específica, tendo por base a unidade de medida adotada.

$\S 3^{\circ} \mathrm{A}$ pessoa natural destinatária das operações de importação poderá ser equiparada a pessoa jurídica, na forma da lei.

$\S 4^{\circ} \mathrm{A}$ lei definirá as hipóteses em que as contribuições incidirão uma única vez. 
meio ambiente, criando uma norma indutora de boas condutas ambientais e ensejando a arrecadação voltada a reparos do meio ambiente deteriorado pela poluição.

Uma eventual CIDE incidente sobre as atividades que emitam grande volume de GEE, nos termos definidos acima poderia, inclusive, servir como instrumento para a viabilização de uma sistemática de pagamento por serviços ambientais, vez que uma parcela dos recursos auferidos pela instituição dessa contribuição poderia ser utilizada para remunerar agentes econômicos que desenvolvam atividades passíveis de fornecimento de serviços ambientais. Nesse caso, o mencionado tributo teria atuação em duas frentes distintas: uma de forma a encarecer atividades poluentes, exigindo um pagamento por parte dos grandes poluidores, e outra de forma a remunerar, com parcela dos recursos arrecadados, as atividades de serviços ambientais.

\section{Conclusão}

São grandes os desafios a serem enfrentados no eixo climático da proteção ambiental. Para o cumprimento das metas previstas na COP-21, especialmente a limitação do aumento da temperatura global a 1,5 graus Celsius, será necessário desenvolver mecanismos de cooperação internacional que sejam capazes de apresentar resultados mais efetivos do que aqueles verificados no Brasil nos últimos anos.

Nesse sentido, tornar-se-á bastante importante que, ao lado de quaisquer metodologias originadas no plano internacional, sejam também instituídos internamente instrumentos de redução de emissões de GEE e de incentivo a atividades que importem sequestro de carbono para atuação paralela aos mecanismos internacionalmente reconhecidos.

Nesse contexto, aponta-se a sistemática do pagamento por serviços ambientais como forma de diluição dos custos de atividades protetivas que, no caso, resultem em redução das emissões de GEE ou sequestro de carbono, e, ainda, a possível instituição de um tributo sobre as emissões de GEE - a tributação do carbono - como formas alternativas de fomento à proteção climática, a serem desenvolvidas em conjunto com os mecanismos já estabelecidos internacionalmente, como o Mecanismo de Desenvolvimento Limpo instituído no âmbito do Protocolo de Kyoto.

Em relação à tributação do carbono, a instituição de uma contribuição de intervenção no domínio econômico sobre atividades que sejam responsáveis por grande parte das emissões de GEE pode se apresentar como melhor alternativa, dentre as espécies tributárias, para que se alcance o fim pretendido vez que, além de possibilitar a efetivação do princípio do poluidor-pagador, ainda será fonte de rendimentos a serem especificamente direcionados para a proteção do meio ambiente.

São Paulo, abril de 2016. 


\section{Referências}

AMARAL, Paulo Henrique do. Direito tributário ambiental. São Paulo: Revista dos Tribunais, 2007.

AMARO, Luciano da Silva. Direito tributário brasileiro. 17. ed. São Paulo: Saraiva, 2011.

AMAZONAS, Maurício de Carvalho. Economia ambiental neoclássica: o debate conceitual nas perspectivas neoclássica, institucionalista e da economia ecológica. In: NOBRE, Marcos; AMAZONAS, Maurício de Carvalho. Desenvolvimento sustentável: a institucionalização de um conceito. Brasília: Edições IBAMA, 2002. p. 107-146.

ARROW, Kennedy J. et al. Is there a role for benefit-cost analysis in environmental, health, and safety regulation? Science, Washington D.C., v. 272, p. 221-222, Apr. 1996.

AVI-YONAH, Reuven S.; UHLMANN, David M. Combating global climate change: why a carbon tax is a better response to global warming than cap and trade. Stanford Environmental Law Journal, Stanford, v. 28, p. 3-50, 2009.

BORBA, Fernanda Estima; FRANÇA, Vladimir da Rocha. O postulado da proporcionalidade na tributação indutora: aplicação e efetividade na defesa do meio ambiente. Revista Tributária e de Finanças Públicas, São Paulo, n. 89, p. 102-125, nov./dez. 2009.

CONSTANZA, Robert; D'ARGE, Ralph et al. The value of the world's ecosystem services and natural capital. Nature, London, v. 387, n. 6.630, p. 253-260, May 1997.

COSTA, Regina Helena. Curso de direito tributário: Constituição e Código Tributário Nacional, 1. ed. São Paulo: Saraiva, 2009.

DALY, Herman E.; FARLEY, Joshua. Ecological economics: principles and applications. Washington: Island Press, 2004.

DERANI, Cristiane. Direito ambiental econômico. 3. ed. São Paulo: Saraiva, 2008.

HARDIN, Garrett. The tragedy of the commons. Science, Washington D.C, v. 162, n. 3.859, p. 1.243-1.248, Dec. 1968.

LEITE, José Rubens Morato (Coord.). Manual de direito ambiental. São Paulo: Saraiva, 2015.

NOBRE, Marcos; AMAZONAS, Maurício de Carvalho Desenvolvimento sustentável: a institucionalização de um conceito. Brasília: IBAMA, 2002.

NUSDEO, Ana Maria de Oliveira. Pagamento por serviços ambientais: sustentabilidade e disciplina jurídica. São Paulo: Atlas, 2012.

PUCCI, Rafael Diniz. Criminalidade ambiental transnacional: desafios para a sua regulação jurídica. 2013. Tese (Doutorado) - Faculdade de Direito, Universidade de São Paulo, São Paulo, 2013. Disponível em: <http://www.teses.usp.br/teses/disponiveis/2/2139/tde-27082013-115114/>. 
PUCCI, Rafael Diniz. Regulierungstechniken für Umweltdelikte und Restorative Justice. Revista da Faculdade de Direito da Universidade de São Paulo, São Paulo, v. 108, p. 531-541, jan./dez. 2013. Disponível em: <http://www.revistas.usp.br/rfdusp/article/view/67995/70852>. Acesso em: 29 abr. 2016.

SCHOUERI, Luís Eduardo. Direito tributário. São Paulo: Saraiva, 2011.

SEROA DA MOTTA, Ronaldo et al. Mudança do clima no Brasil: aspectos econômicos, sociais e regulatórios. Brasília: IPEA, 2011.

TURNER, R. Kerry; PEARCE, David W.; BATEMAN, Ian. Environmental economics: an elementary introduction. Baltimore: John Hopkins University Press, 1993.

VEIGA, José Eli da. A desgovernança mundial da sustentabilidade. 1. ed. São Paulo: Editora 34, 2013.

. Para entender o desenvolvimento sustentável. 1. ed. São Paulo: Editora 34, 2015.

WESTERLUND, Staffan. Theory for sustainable development; towards or against? Sustainable development in international and national law. Groningen: Europa Law Publishing, 2008.

WINTER, Gerd. Proporcionalidade "eco-lógica”: um princípio jurídico emergente para a natureza? Veredas do Direito: Direito Ambiental e Desenvolvimento Sustentável, Belo Horizonte, v. 10, n. 20, p. 55-78, jul./dez. 2013. 